\title{
Influence of lesion level on the cardioventilatory adaptations in paraplegic wheelchair athletes during muscular exercise
}

\author{
PL Bernard*,1, J Mercier ${ }^{2}$, A Varray ${ }^{2}$ and C Prefaut ${ }^{2}$ \\ ${ }^{1}$ Laboratoire de Biologie et de Biomécanique de l'exercice, UFR APS, Nice France; ${ }^{2}$ Laboratoire de Physiologie des \\ Interactions, CHU Arnaud de Villeneuve, 371 avenue Doyen Giraud, 34295 Montpellier Cedex 5, France
}

Objectives: To characterize the influence of neurological lesion level on the cardiorespiratory and ventilatory responses of two groups of paraplegic athletes during incremental exercise on a treadmill and in the usual conditions for wheelchair exercise.

Methods: Cardioventilatory responses evaluated in two groups of paraplegic wheelchair sportsmen designated as high paraplegic athletes (HPA) and low paraplegic athletes (LPA). After 2 min of data collection at rest and 3 min of warm-up at $4 \mathrm{~km} \cdot \mathrm{h}^{-1}$, treadmill speed was increased by $1 \mathrm{~km} \cdot \mathrm{h}^{-1}$ every minute until exhaustion. During this test, ventilation and its components, as well as respiratory exchanges, were measured breath by breath (C.P.X. Medical Graphics) every minute by taking the mean of the last $20 \mathrm{~s}$ of each increment.

Results: Spirometric values presented no significant differences between groups. At rest, no significant difference was observed between the two groups for all cardiorespiratory and ventilatory values obtained during the treadmill test. At submaximal exercise, all variables increased with the augmentation in workload. With the exception of $\mathrm{R}$, there were no significant differences in the classic cardiorespiratory parameters $\left(\dot{V} \mathrm{O}_{2}, \dot{V} \mathrm{CO}_{2}, \mathrm{HR}, \dot{V} \mathrm{E}\right)$ between the two groups of paraplegics. For the ventilatory parameters, we observed significant differences between the two groups, with values of $\mathrm{f}$ and $\mathrm{It} / \mathrm{Trf}$ significantly higher $(0.01<P<0.001)$ and values of $\operatorname{Trf}$ and $\mathrm{Vt}$ significantly lower $(0.01<P<0.001)$ for HPA versus LPA. We observed changes in breathing pattern, ie, in $\mathrm{f}, \mathrm{Vt}, \operatorname{Trc}$ and It/Trc, were significantly different between groups, with significantly higher values of $\mathrm{f}$ and It/Trc for HPA. We noted a ventilatory disturbance which was manifested by values of breathing frequency and tidal volume during exercise that were significantly different between groups. During maximal exercise, we observed no significant differences between the two groups concerning cardiorespiratory and ventilatory values. Despite the absence of significant differences, the more linear time course of the ensemble of HPA flows, the achievement of a greater number of work loads, and the higher maximal values indicate a better capacity for adaptation to exercise in the group of lower thoracic paraplegics.

Conclusion: These results raise questions about the influence of neurological level and further research is needed to define with more precision the capacities of readaptation of the different cardiovascular and respiratory functions, as well as the training methods best adapted to the optimization of physical capacities.

Spinal Cord (2000) 38, 16-25

Keywords: paraplegic; muscular exercise; aerobic; cardio-respiratory; sport

\section{Introduction}

Several physiological complications affect the physical capacities of spinal cord-injured (SCI) individuals. From a neurovegetative point of view, damage to humoral, ${ }^{1-3}$ thermal, ${ }^{4-6}$ or local circulatory regulation affects cardiovascular functioning. ${ }^{7-9}$ Damage to the circulatory regulation may be manifested by vasoplegia, reduced venous return or reduced activity of the muscular pump. In addition, the patient may be subject to respiratory problems, ${ }^{10-12}$ depending on the lesion level, with

*Correspondence: PL Bernard, Laboratoire de Biologie et de Biomécanique de I'Exercice, UFR APS, 261 route de Grenoble, 06202 Nice, France capacities being weaker at higher lesion levels. ${ }^{13-15}$ Numerous studies on cycle ergometer or treadmill have defined the mechanical and physiological responses of SCI patients during muscular exercise. Studies of the wheelchair itself, ie, the different structures and specific adjustments, have guided the search to optimize the 'wheelchair-person' system. ${ }^{16-19}$ The characterization of the capacities of both paraplegics and tetraplegics has also been undertaken, but further investigation into the cardiorespiratory and ventilatory adaptations that occur during muscular work is needed. Although several studies have defined the relationship between lesion level and losses in cardiorespiratory capacity, ${ }^{20-22}$ the physio- 
pathologic bases need to be better understood in order to improve rehabilitation and exercise training programs. This study was designed to determine the influence of neurological lesion level on the cardiorespiratory and ventilatory responses of two groups of paraplegic athletes during progressive, continuous maximal exercise on a treadmill and in the usual conditions for wheelchair exercise. Because of the loss of function in certain muscles involved in exercise hyperventilation and the lack of this type of research, we studied the breathing pattern of these paraplegic patients and tried to characterize the influence of lesion level on the difficulties of adaptation to exercise.

\section{Methods}

\section{Subjects}

The study involved two groups of athletes with paraplegia (Table 1). The first group was composed of six with lesion levels between the fourth and eighth thoracic vertabrae (T4-T8). These individuals were nationally ranked wheelchair athletes and were designated as high paraplegic athletes (HPA). According to the international classification of wheelchair athletes, this group was within classes 2 and 3 (neurological level respectively between T1-T5 and T6-T10). The second group of athletes had a lesion level between the eleventh thoracic vertabrae and the fifth lumbar vertabrae, and they were designated as low paraplegic athletes (LPA). They were also nationally ranked athletes and were classed 4 (neurological level between T11-L3) according to the international classification.

\section{Equipment}

Lung function testing was performed by plethysmography (System 2800 Autobox, Sensormedics, CA, USA) and lung volumes and bronchial flows were measured. A maximal incremental exercise test was then conducted on a Sopur treadmill equipped with rollers to permit the control of propulsion velocity and

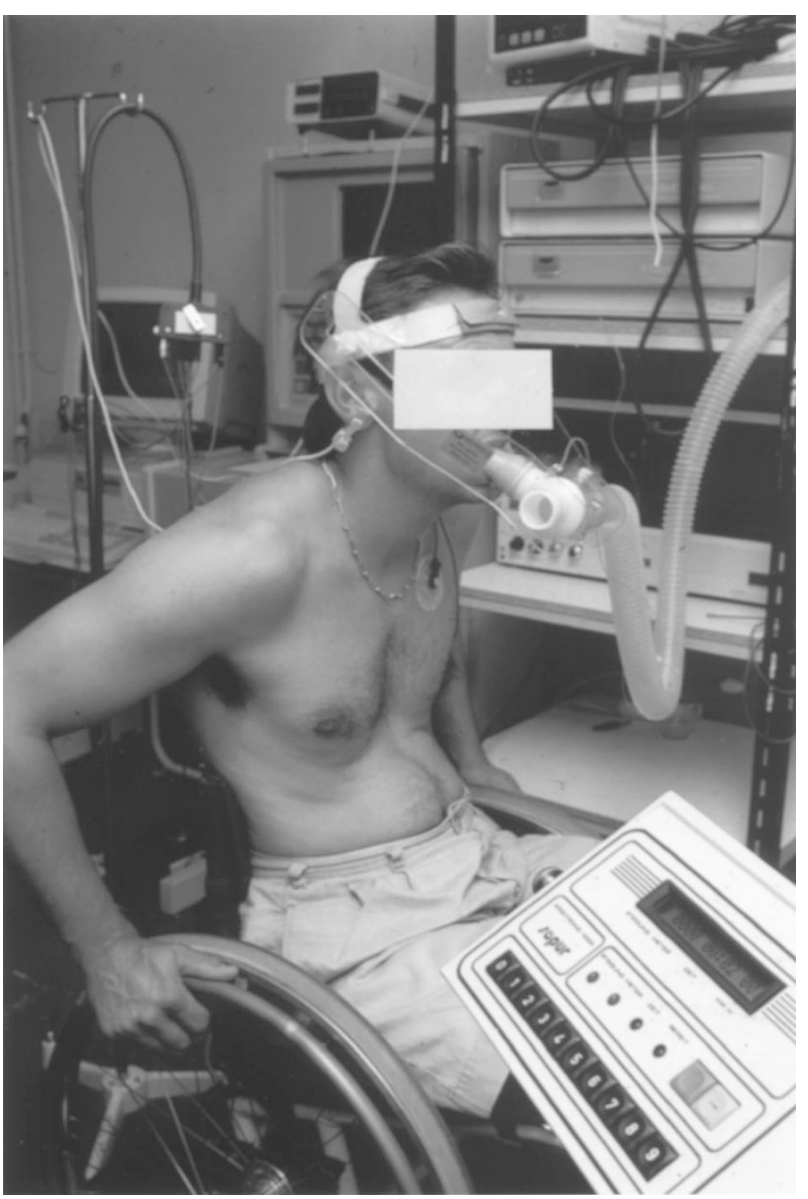

Figure 1 The expiratory gas collection system during the treadmill test

Table 1 Anthropometric and neurological characteristics of the two groups of paraplegics

\begin{tabular}{|c|c|c|c|c|c|c|c|}
\hline$H P A$ & Age & Weight (kg) & Height $(\mathrm{cm})$ & Level & Lesion & Trouble & Sport \\
\hline R.F & 30 & 55 & 170 & T5 & complete & spastic & basket \\
\hline A.T & 29 & 60 & 170 & T4-T6 & complete & spastic & tennis \\
\hline B.A & 31 & 71 & 185 & $\mathrm{~T} 4$ & complete & spastic & tennis \\
\hline R.P & 33 & 66 & 177 & $\mathrm{~T} 8$ & complete & spastic & tennis \\
\hline C.L & 30 & 55 & 168 & T5 & complete & spastic & tennis \\
\hline R.A & 37 & 70 & 178 & T5 & complete & spastic & tennis \\
\hline $\mathrm{m}$ & 31.6 & 62.8 & 174.6 & & & & \\
\hline $\mathrm{sd}$ & 2.94 & 7.19 & 6.50 & & & & \\
\hline \multicolumn{8}{|l|}{$L P A$} \\
\hline B.P & 27 & 70 & 180 & L3 & incomplete & flacid & tennis \\
\hline B.L & 30 & 53 & 163 & $\mathrm{~T} 12$ & incomplete & spastic & tennis \\
\hline G.S & 24 & 63 & 170 & $\mathrm{~T} 12$ & complete & spastic & tennis \\
\hline B.S & 29 & 78 & 184 & $\mathrm{~T} 11$ & complete & spastic & racing \\
\hline G.M & 28 & 70 & 182 & $\mathrm{~T} 12$ & complete & flacid & tennis \\
\hline N.E & 32 & 77 & 178 & $\mathrm{~T} 12-\mathrm{L} 1$ & complete & flacid & basket \\
\hline $\mathrm{m}$ & 28.3 & 68.5 & 176.1 & & & & \\
\hline $\mathrm{sd}$ & 2.73 & 9.35 & 8.06 & & & & \\
\hline
\end{tabular}

HPA: high paraplegic athletes. LPA: low paraplegic athletes 


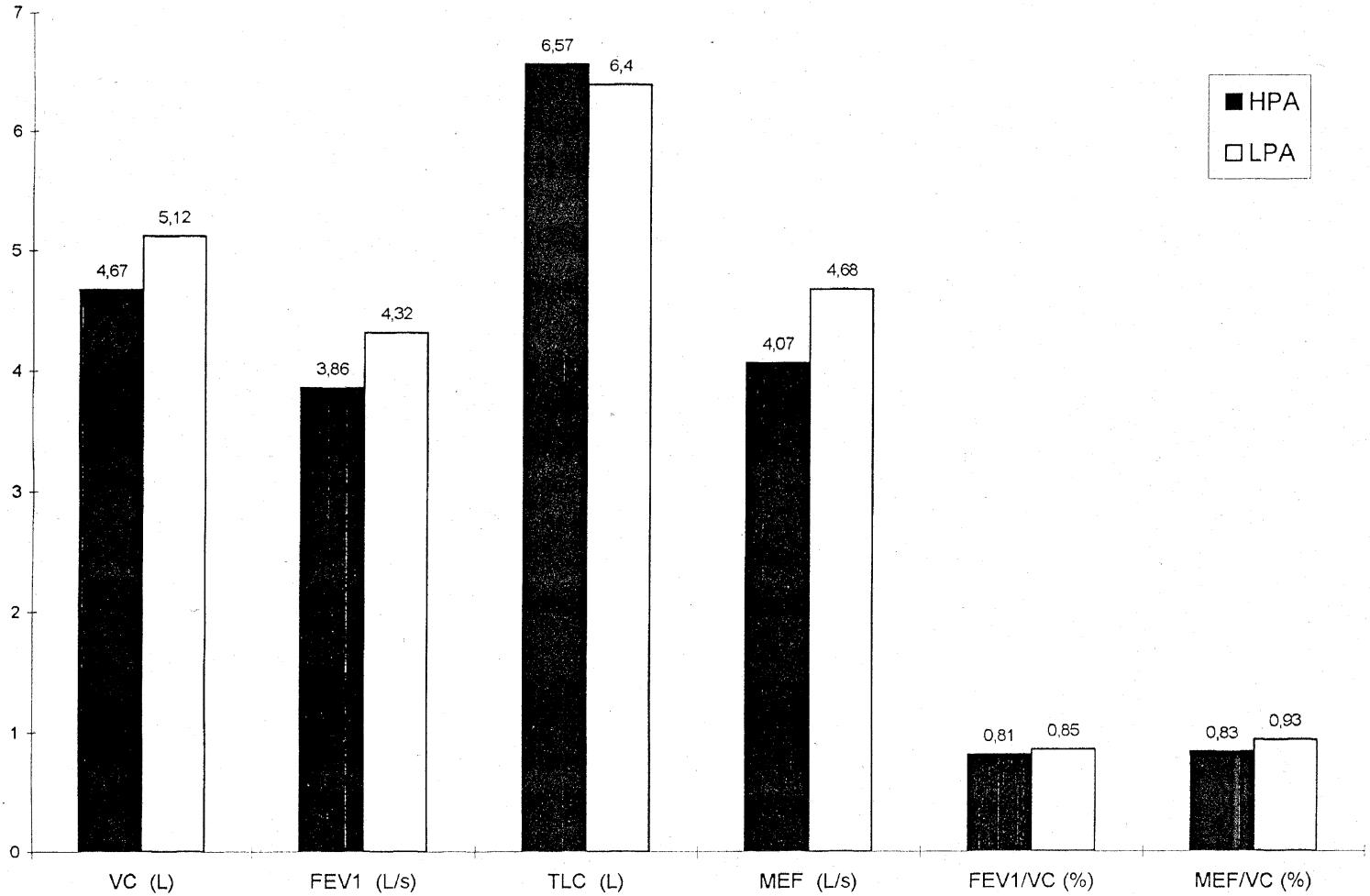

Figure 2 Values for lung volumes and bronchial flow for the two groups of HPA and LPA. (VC: vital capacity; FEV ${ }_{1}$ : forced expiratory volume in one second; TLC: total lung capacity; MEF: maximal expiratory flow)

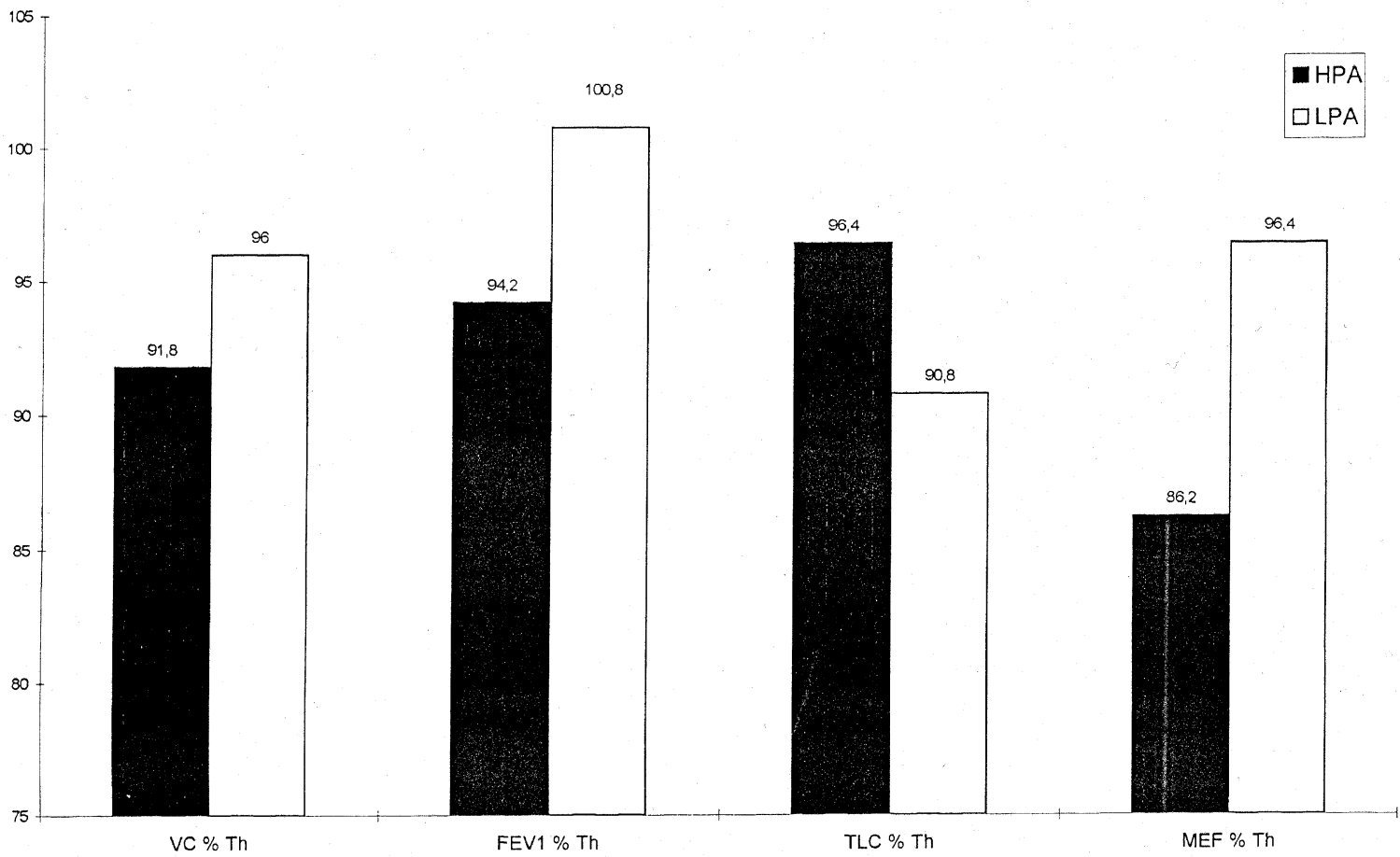

Figure 3 Spirometric values of the two groups compared to the theoretical norms. (VC/\%Th, TLC/\%Th, FEV $1 / \% \mathrm{TH}, \mathrm{MEF} /$ $\% \mathrm{Th})$ and normalisation of $\mathrm{FEV}_{1}$ and $\mathrm{MEF}$ by $\mathrm{VC}\left(\mathrm{FEV}_{1} / \mathrm{VC}, \mathrm{MEF} / \mathrm{VC}\right)$ 
the regularity of increments (Figure 1). Each subject used his own wheelchair which was adjusted for optimal performance. During this test, ventilation and its components, as well as respiratory exchanges, were measured breath by breath (C.P.X. Medical Graphics). Oxygen uptake $\left(\dot{V} \mathrm{O}_{2}\right)$, carbon dioxide output $\left(\dot{V} \mathrm{CO}_{2}\right)$,

Table 2 Cardio-ventilatory values of the two groups of paraplegics at rest

\begin{tabular}{|c|c|c|c|c|c|c|c|c|c|c|c|c|}
\hline LO & & $\dot{V} \mathrm{O}_{2}$ & $\dot{V} \mathrm{CO}_{2}$ & $H R$ & $\dot{V} \mathrm{E}$ & $R$ & $f$ & $T i$ & Tot & $V t$ & $V t / T i$ & Ti/Tot \\
\hline HPA & $\mathrm{m}$ & 235.8 & 223 & 80 & 8.68 & 0.94 & 15.8 & 2.54 & 4.02 & 0.65 & 0.26 & 0.64 \\
\hline$(n=6)$ & $\mathrm{SE}$ & 21.73 & 19.99 & 5.26 & 1.92 & 0.02 & 1.06 & 0.14 & 0.19 & 0.07 & 0.03 & 0.04 \\
\hline LPA & $\mathrm{m}$ & 350.2 & 378.2 & 80.2 & 14.8 & 1.05 & 13.6 & 2.84 & 4.92 & 1.17 & 0.41 & 0.57 \\
\hline \multirow[t]{2}{*}{$(n=6)$} & $\mathrm{SE}$ & 109.7 & 75.988 & 15.56 & 4.94 & 0.14 & 3.57 & 0.45 & 0.59 & 0.25 & 0.06 & 0.04 \\
\hline & $P$ & NS & NS & NS & NS & NS & NS & NS & NS & NS & NS & NS \\
\hline
\end{tabular}

Oxygen uptake $\left(\dot{V} \mathrm{O}_{2}\right)$, carbon dioxide output $\left(\dot{V} \mathrm{CO}_{2}\right)$, heart rate $(\mathrm{HR})$, minute ventilation $(\dot{V} \mathrm{E})$, respiratory exchange ratio $(\mathrm{R})$, heart rate (HR), tidal volume (Vt), the ratio of inspiratory time (It) to the total respiratory cycle (Trc), mean inspiratory flow (Vt/It) and breathing frequency (f)

Table 3 Submaximal cardiorespiratory values for the two groups of paraplegics

\begin{tabular}{|c|c|c|c|c|c|c|c|c|c|}
\hline & & & & $P 1$ & $P 2$ & P3 & P4 & P5 & P6 \\
\hline \multirow[t]{4}{*}{$\dot{V} \mathrm{O}_{2}$} & HPA & & $\mathrm{m}$ & 772.20 & 797.20 & 854.20 & 1006.00 & 1114.20 & 1324.00 \\
\hline & $(n=6)$ & NS & SE & 124.80 & 18.93 & 39.37 & 37.96 & 42.57 & 65.04 \\
\hline & LPA & & $\mathrm{m}$ & 667.20 & 782.80 & 891.60 & 1106.00 & 1223.00 & 1607.00 \\
\hline & $(n=6)$ & & SE & 86.65 & 80.12 & 77.42 & 30.66 & 59.20 & 73.90 \\
\hline \multirow{4}{*}{$\dot{V} \mathrm{CO}_{2}$} & HPA & & $\mathrm{m}$ & 754.40 & 770.00 & 848.00 & 1027.00 & 1286.00 & 1631.00 \\
\hline & & NS & SE & 185.80 & 90.74 & 59.81 & 45.61 & 81.35 & 108.91 \\
\hline & SPB & & $\mathrm{m}$ & 625.60 & 725.00 & 844.00 & 1062.00 & 1201.00 & 1602.00 \\
\hline & & & SE & 85.50 & 97.56 & 90.55 & 30.41 & 76.64 & 131.94 \\
\hline \multirow[t]{4}{*}{ HR } & HPA & & $\mathrm{m}$ & 100.20 & 101.20 & 104.00 & 129.80 & 143.40 & 159.20 \\
\hline & & NS & SE & 5.54 & 6.00 & 5.34 & 4.08 & 23.57 & 8.98 \\
\hline & SPB & & $\mathrm{m}$ & 99.60 & 104.80 & 101.40 & 119.40 & 129.20 & 138.80 \\
\hline & & & SE & 5.79 & 6.30 & 9.58 & 7.42 & 5.58 & 6.46 \\
\hline \multirow[t]{4}{*}{$\dot{V} \mathrm{E}$} & HPA & & $\mathrm{m}$ & 26.44 & 26.68 & 29.92 & 34.84 & 45.14 & 56.70 \\
\hline & & NS & SE & 6.41 & 4.21 & 3.63 & 3.31 & 3.09 & 4.00 \\
\hline & SPB & & $\mathrm{m}$ & 23.68 & 28.72 & 32.18 & 36.96 & 41.88 & 50.00 \\
\hline & & & SE & 3.20 & 4.65 & 4.43 & 3.12 & 3.40 & 2.90 \\
\hline \multirow[t]{4}{*}{$\mathrm{R}$} & HPA & & $\mathrm{m}$ & 0.96 & 0.98 & 1.04 & 1.03 & 1.14 & 1.23 \\
\hline & & $* *$ & SE & 0.11 & 0.09 & 0.05 & 0.03 & 0.03 & 0.04 \\
\hline & SPB & & $\mathrm{m}$ & 0.92 & 0.90 & 0.92 & 0.96 & 0.98 & 1.00 \\
\hline & & & SE & 0.09 & 0.08 & 0.05 & 0.04 & 0.04 & 0.08 \\
\hline \multirow[t]{4}{*}{ TI } & HPA & & $\mathrm{m}$ & 1.66 & 1.26 & 1.16 & 1.24 & 0.90 & 0.72 \\
\hline & & NS & SE & 0.35 & 0.05 & 0.08 & 0.10 & 0.09 & 0.10 \\
\hline & SPB & & $\mathrm{m}$ & 1.92 & 1.24 & 1.28 & 1.24 & 1.18 & 0.94 \\
\hline & & & SE & 0.44 & 0.12 & 0.08 & 0.11 & 0.14 & 0.11 \\
\hline \multirow{4}{*}{$\mathrm{VT} / \mathrm{TI}$} & HPA & & $\mathrm{m}$ & 0.79 & 0.83 & 0.94 & 1.02 & 1.39 & 2.11 \\
\hline & & NS & SE & 0.32 & 0.19 & 0.15 & 0.20 & 0.14 & 0.17 \\
\hline & SPB & & $\mathrm{m}$ & 0.72 & 1.08 & 1.13 & 1.44 & 1.76 & 2.14 \\
\hline & & & SE & 0.07 & 0.15 & 0.17 & 0.18 & 0.32 & 0.37 \\
\hline
\end{tabular}

Oxygen uptake $\left(\dot{V} \mathrm{O}_{2}\right)$, carbon dioxide output $\left(\dot{V} \mathrm{CO}_{2}\right)$, heart rate $(\mathrm{HR})$, minute ventilation $(\dot{V} \mathrm{E})$, respiratory exchange ratio $(\mathrm{R})$, heart rate $(\mathrm{HR})$, inspiratory time $(\mathrm{It})$ and mean inspiratory flow $(\mathrm{BT} / \mathrm{It})$ ). (NS: non significant. $* * P<0.01)$

Table 4 Maximal cardio-vantilatory values for the two groups of paraplegics

\begin{tabular}{|c|c|c|c|c|c|c|c|c|c|c|c|c|}
\hline$P \max$ & & $\dot{V} \mathrm{O}_{2}$ & $\dot{V} \mathrm{CO}_{2}$ & $H R$ & $V E$ & $R$ & $f$ & $T i$ & Tot & $V t$ & $V t / T i$ & Ti/Tot \\
\hline HPA & $\mathrm{m}$ & 1786 & 2498 & 183 & 87.08 & 1.39 & 51.8 & 0.44 & 1.2 & 1.72 & 4.03 & 0.36 \\
\hline$(n=6)$ & $\mathrm{SE}$ & 138.14 & 252.51 & 5.37 & 9.7 & 0.08 & 5.67 & 0.06 & 0.13 & 0.21 & 0.34 & 0.03 \\
\hline LPA & $\mathrm{m}$ & 2346 & 3064 & 168.4 & 110.7 & 1.31 & 51 & 0.58 & 1.36 & 2.16 & 5.26 & 0.39 \\
\hline$(n=6)$ & $\mathrm{SE}$ & 258.9 & 313.05 & 7.6 & 21.82 & 0.02 & 8.96 & 0.17 & 0.21 & 0.19 & 1.62 & 0.06 \\
\hline & $P$ & NS & NS & NS & NS & NS & NS & NS & NS & NS & NS & NS \\
\hline
\end{tabular}

Oxygen uptake $\left(\dot{V} \mathrm{O}_{2}\right)$, carbon dioxide output $\left(\dot{V} \mathrm{CO}_{2}\right)$, heart rate $(\mathrm{HR})$, minute ventilation $(\dot{V} \mathrm{E})$, respiratory exchange ratio $(\mathrm{R})$, heart rate $(\mathrm{HR})$, tidal volume $(\dot{V} \mathrm{t})$, the ratio of inspiratory time (It) to the total respiratory cycle (Trc), mean inspiratory flow $(\dot{V} \mathrm{t} / \mathrm{It})$ and breathing frequency (f) 
minute ventilation $(\dot{V} \mathrm{E})$, respiratory exchange ratio $(\mathrm{R})$, heart rate $(\mathrm{HR})$, tidal volume $(\mathrm{Vt})$, the ratio of inspiratory time (It) to the total respiratory cycle (Trc), mean inspiratory flow (Vt/It) and breathing frequency (f) were calculated every minute by taking the mean of the last $20 \mathrm{~s}$ of each increment.

The subjects breathed through a low-resistance valve (Valve 2700 Hans Rudolph) and wide-diameter tubing connected to a type-3 pneumotachograph located on the expiratory circuit and connected to a pressure transducer (Valydine D.P. 250-14). The fractions of expired oxygen and carbon dioxide were measured, respectively, with a zirconium $\mathrm{O}_{2}$ analyzer and an infrared $\mathrm{CO}_{2}$ analyzer. Before each test the volume was calibrated with a 3-1 pump and the analyzers were standardized with a bottle containing $12 \% \quad \mathrm{O}_{2}$ and $5 \% \mathrm{CO}_{2}$. Heart rate was continuously monitored with an electrocardiograph (Quinton 3000) with analysis of derivations D2, V2 and V5.

\section{Protocol}

Before testing, each subject underwent a clinical examination, a resting electrocardiogram and spirometry to determine lung volumes and bronchial flows, vital capacity (VC) and total lung capacity (TLC). Bronchial flow was determined from forced expiratory volume in $1 \mathrm{~s}\left(\mathrm{FEV}_{1}\right)$ and the maximum expiratory flow (MEF). We also obtained four indices by comparing these values to the normal theoretical values (VC\%Th, TLC $\% \mathrm{Th}, \mathrm{FEV}_{1} \% \mathrm{Th}, \mathrm{MEF} \% \mathrm{Th}$ ) and normalized $\mathrm{FEV}_{1}$ and $\mathrm{MEF}$ by $\mathrm{VC}\left(\mathrm{FEV}_{1} / \mathrm{VC}\right.$, $\mathrm{MEF} / \mathrm{VC}$ ). For the incremental test, the wheelchair was fixed to the treadmill rollers and the subject was equipped with the expired gas collection system. After 2 min of data collection at rest and 3 min of warm-up at $4 \mathrm{~km} \cdot \mathrm{h}^{-1}$, treadmill speed was increased by $1 \mathrm{~km} \cdot \mathrm{h}^{-1}$ every minute until exhaustion. Recovery data were recorded for $5 \mathrm{~min}$.

\section{Statistical analysis}

All values are expressed as mean \pm SEM. A means comparison test for independent samples was used to compare the spirometric values and the cardiorespiratory and ventilatory values measured at rest and at maximal exercise. A two-way analysis of variance (ANOVA) was used to compare the two groups during submaximal exercise. The significance level was set at $P<0.05$.

\section{Results}

The spirometric values for the two groups are presented in Figures 2 and 3. There were no significant differences between groups. We observed, however, that TLC was the only variable that was higher in HPA than in LPA $(6.57 / 6.401)$ (Figure 2). The values were slightly lower than the theoretical norms (Figure 3) except for minute $\mathrm{FEV}_{1} \% \mathrm{Th}$ which reached a value of $100.8 \% . \mathrm{FEV}_{1} / \mathrm{VC}$ was slightly higher than the norm (0.75) both for HPA $(0.81)$ and LPA (0.85).

The cardiorespiratory and ventilatory values obtained during the treadmill test are presented in Tables $2-4$ and in Figure $4 \mathrm{a}-\mathrm{d}$. At rest (Table 2), no significant difference was observed between the two groups.

At submaximal exercise, all variables increased with the augmentation in workload. With the exception of $\mathrm{R}$, there were no significant differences in the classic cardiorespiratory parameters $\left(\dot{V} \mathrm{O}_{2}, \dot{V} \mathrm{CO}_{2}, \mathrm{HR}, \dot{V} \mathrm{E}\right)$ between the two groups (Table 3 ). For the ventilatory parameters, we observed significant differences between the two groups, with values of $\mathrm{f}$ and It/Trf significantly higher $(0.01<P<0.001)$ and values of Trf and Vt significantly lower $(0.01<P<0.001)$ for HPA versus LPA (Table 4 and Figure $4 \mathrm{a}-\mathrm{d}$ ).

At maximal exercise, there were no significant differences between the two groups (Table 4). However, LPA showed higher mean values of $\dot{V O}{ }_{2}$ $(2346 / 1786 \mathrm{ml} / \mathrm{min}), \quad \dot{V C O}_{2}(3064 / 2498 \mathrm{ml} / \mathrm{min}), \quad \mathrm{Vt}$ $(1.16 / 1.72 \mathrm{ml}), \mathrm{Vt} / \mathrm{It}(5.26 / 4.03 \mathrm{ml} / \mathrm{s})$ and It/Trf $(0.39 /$ $0.36)$; whereas HPA showed higher values of HR (183/ $168 \mathrm{bt} / \mathrm{min})$ and $\mathrm{VE}(110 / 87 \mathrm{l} / \mathrm{min})$. The values of $\mathrm{R}, \mathrm{f}$ and It/Trc were approximately the same for the two groups.

\section{Discussion}

At rest, we observed no significant differences for the cardiorespiratory and ventilatory parameters measured in the two groups of athletes with paraplegia. At submaximal exercise, the increase in workload led to increases in $\dot{V} \mathrm{O}_{2}, \dot{V} C_{2}, \mathrm{HR}$ and $\dot{V} \mathrm{E}$. There were no significant differences in these four parameters between the two groups. Regarding $\dot{V O}_{2}$, the recruitment of efficient muscle mass in the scapular belt and the arms may explain the close values. Even though the athletes belonged to three different athletic classes, the adaptations were similar and did not seem to limit performance, which depends on both central factors of the cortico-medullary centers and peripheral factors acheminant the information of chemoreceptors of the skeletal muscles. ${ }^{23}$ Differences in the muscle mass used to ensure propulsion at a given velocity may explain the absence of significant differences in the evolution of $\dot{V} \mathrm{O}_{2}$ between the two groups. At the same level of exercise, it is possible that the high paraplegics needed a greater number of sublesional muscles to accomplish the task because of their difficulty in maintaining balance in a seated position. ${ }^{24}$ This hypothesis may be associated with the earlier achievement of maximal values that characterized HPA. Indeed, we observed that the maximal values for LPA were systematically reached after those for HPA. This finding indicates the need for further investigation with a bigger population in order to determine the cardiorespiratory adaptations expressed in percentage of $\dot{V} \mathrm{CO}_{2}$ flow rather than as 
a function of the workload expressed as the velocity of displacement.

The values of $\dot{V} \mathrm{O}_{2}, \quad \dot{V} \mathrm{CO}_{2}, \mathrm{HR}$, and $\dot{V} \mathrm{E}$ were overall in agreement with those of the literature which generally indicates a relationship between lesion level and the diminution in cardiorespiratory capacities. ${ }^{21,25,26}$ At a given level of exercise, the HR values of low paraplegics tend to be lower than those of high paraplegics, ${ }^{27}$ and our results confirmed this observation. Downey ${ }^{5}$ and Sawka et $a l^{6}$ noted disturbances in thermo-regulation and the loss of sublesional muscular contraction in thoracic paraplegics, which influence venous return in the extremities and which would explain the difficulties in adaptation. We also observed a more rapid increase in HR and $\dot{V} \mathrm{E}$ in HPA, which seems to be necessary for adaptation to exercise due to the lack of sublesional vasoconstriction and of venous return in inactive territories.

The changes in breathing pattern, ie, in $\mathrm{f}, \mathrm{Vt}, \mathrm{Trc}$ and It/Trc, were significantly different between groups, with significantly higher values of $\mathrm{f}$ and It/Trc for HPA. Although these exercise responses were different, the spirometric values at rest did not differ significantly. Indeed, the values of lung volume, which represents the properties of the thoracic wall and the pulmonary parenchyma, and the values of bronchial flow, which indicates airways function, did not show significant differences. Although certain ventilatory muscles were affected, which disrupts diaphragmatic and thoracic compliance, ${ }^{11,28}$ the spirometric values at rest of HPA and LPA were not statistically different. Our measurements were similar to those reported by Jaeger-Denavit et $a l^{29}$ for $\mathrm{VC}$ and $\mathrm{FEV}_{1}$ and by FulgMeyer $^{30}$ for TLC and ERV, and were higher than the values of $\mathrm{FEV}_{1}$ and $\mathrm{VC}$ in a large sample reported by Cooper et al. ${ }^{13}$ Our values for VC, which were slightly lower than the normal values, indicate a limitation in respiratory reserve, that is, in the possibility of increasing the pulmonary ventilation. Moreover, the HPA showed 'slight' signs of a restrictive syndrome with a normal to slightly higher $\mathrm{FEV}_{1} / \mathrm{VC}$ index and a slightly lower $\mathrm{FEV}_{1}$ in comparison with the theoretical norm, and lower than that of the LPA. During incremental exercise, the increase in $\dot{V} \mathrm{E}$ was associated with substantial changes in breathing pattern characterized by increases in $\mathrm{Vt}, \mathrm{f}, \mathrm{Vt} / \mathrm{It}$ and $\mathrm{It} / \mathrm{Trc}$ and a drop in It. Beyond a certain point, Vt can no longer increase and the increase in ventilation is assured by an increase in frequency. These responses, which are characteristic of incremental exercise performance in general, were observed in both groups of paraplegic athletes. When respiratory muscles are affected by SCI, such as the abdominal and intercostal muscles that contribute to expiration, the breathing pattern is also affected. Below a certain lesion level, the sensory-motor function no longer exists. We noted a ventilatory disturbance which was manifested by values of breathing frequency and tidal volume during exercise that were significantly different between groups. Indeed, for the first increment of exercise, the two groups had similar values of Vt. Over the course of the exercise test, the LPA progressively increased this volume and had a higher value at the last submaximal workload than the HPA (2.16/ $1.72 \mathrm{ml}$ ). In contrast, the HPA seemed to ensure continued effort by a rapidly increasing f. From the first workload, the values of HPA were higher than those of LPA and this tendency became more marked over the course of the submaximal workloads. These lower values of $\mathrm{Vt}$ and the significant increase in $\mathrm{f}$, with no significant change in VE, confirm the work of Loveridge et $a l^{31}$ and may be the result of certain respiratory muscles affected by SCI.

The afferent nerves of the respiratory muscles, which contribute minimally to ventilatory control at rest, significantly influenced the breathing pattern during exercise. The nervous structures responsible for respiratory activity and rhythmicity, located at the bulbar and cervical level, were not affected in the paraplegic subjects that we studied. In contrast, a lesion in region T4-T10 affects certain ventilatory muscles such as the abdominals and a part of the internal intercostal used during forced expiration. The afferent nerves from the thoracic cage and diaphragm muscles are in part composed of small-diameter fibers of type III and IV, which play a role in ventilatory compensation, ${ }^{32}$ and whose dysfunctioning is probable in SCI individuals. The loss of activity in these muscles is expressed by a rapid increase in breathing frequency because of the lack of variation in tidal volume. When the medullary region is affected and there is a lack of information from the peripheral territories (mechanoreceptors, neuromuscular spindles, Golgi tendinous organs, chemoreceptors, etc.), ${ }^{33,6}$ there is surely a disturbance of ventilatory control and the adaptation to exercise. A study of ventilatory control by measurement of PO.1 is currently underway to define the relationships between lesion level and the alteration in the central command of the respiratory muscles.

During maximal exercise, we observed no significant differences between the two groups concerning cardiorespiratory and ventilatory values. There are, however, differences that the statistical analysis cannot account for due to the small size and classic heterogeneity of paraplegic groups. Despite the absence of significant differences, the more linear time course of the ensemble of HPA flows, the achievement of a greater number of work loads, and the higher maximal values indicate a better capacity for adaptation to exercise in the group of lower thoracic paraplegics.

The lower values of $\dot{V} \mathrm{O}_{2}$ in HPA agreed with most of the data in the literature indicating the effect of lesion level on $\mathrm{VO}_{2}$ max. ${ }^{20,26,34}$ The values of HPA and LPA were similar to those of Hopman et al ${ }^{35}$ for their two groups of classes 2 and 3, but higher than those of Hooker et $a l^{36}$ for these same two athletic classes. Wheelchair-dependent patients use the mus- 
cles of the upper extremities and the scapular belt daily during wheelchair locomotion, and we can assume that good local cardiovascular adaptability characterizes these muscle groups that are responsible for propulsion. However, lower maximal values characterize the high paraplegics and may indicate greater fatiguability resulting from the absence of vaso-motor control in a greater sublesional area. For ventilatory flow, the values of the two groups were not significantly different and agree in part with the available literature. Although the values of HPA (87.1 1/min) seemed high compared to those of Coutts

a

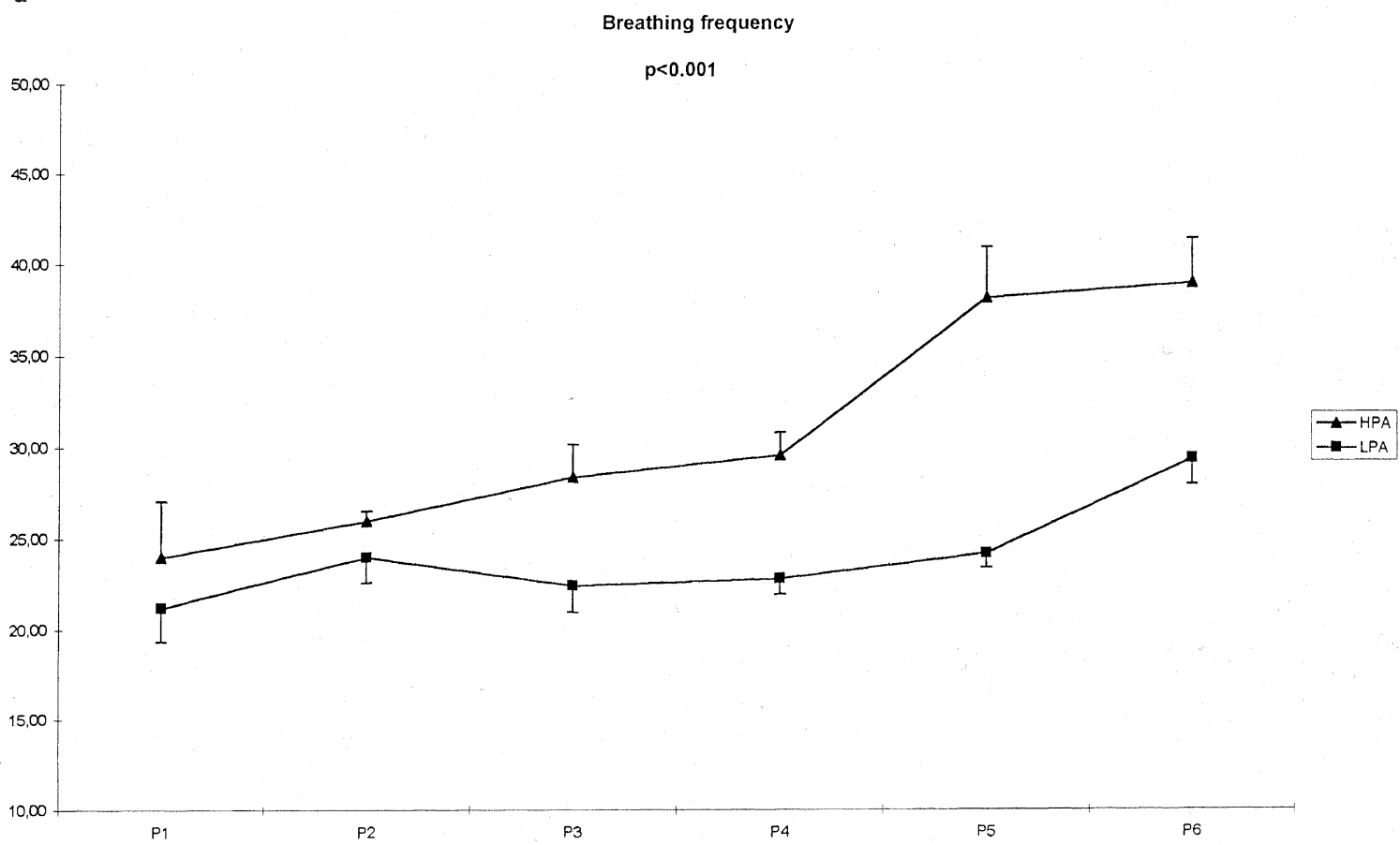

b

Total respiratory cycle

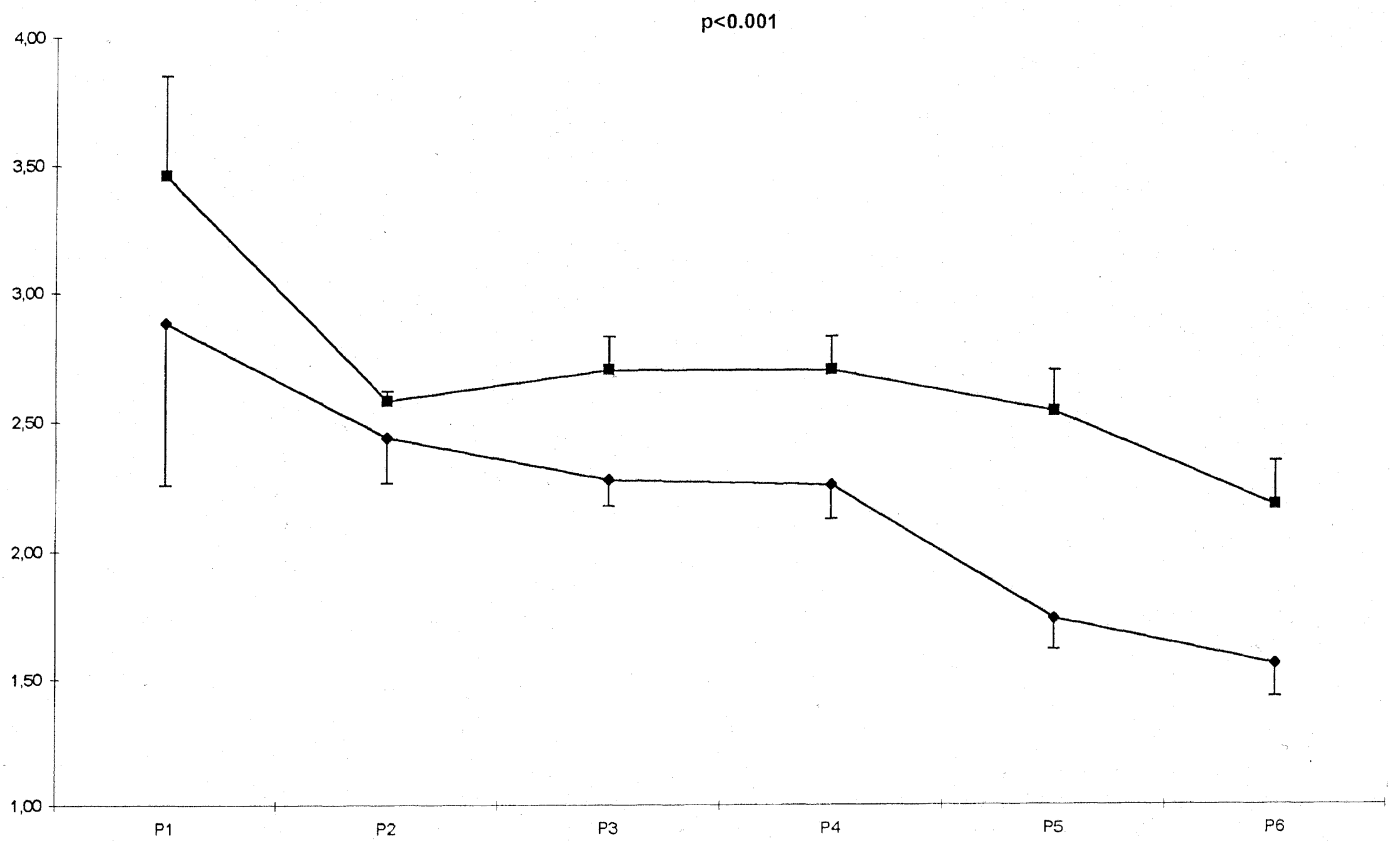


et $a l^{20}$ and Van Loan et $a l^{22}$ they were close to those measured by Hooker et $a l^{37}$ in seven class-3 wheelchair athletes tested during exercise on a manual ergocycle.
The different protocols used, the lack of detail regarding the characteristics of the subjects, and the inclusion of paraplegics of different lesion levels all make it difficult to compare our work with others. The

C

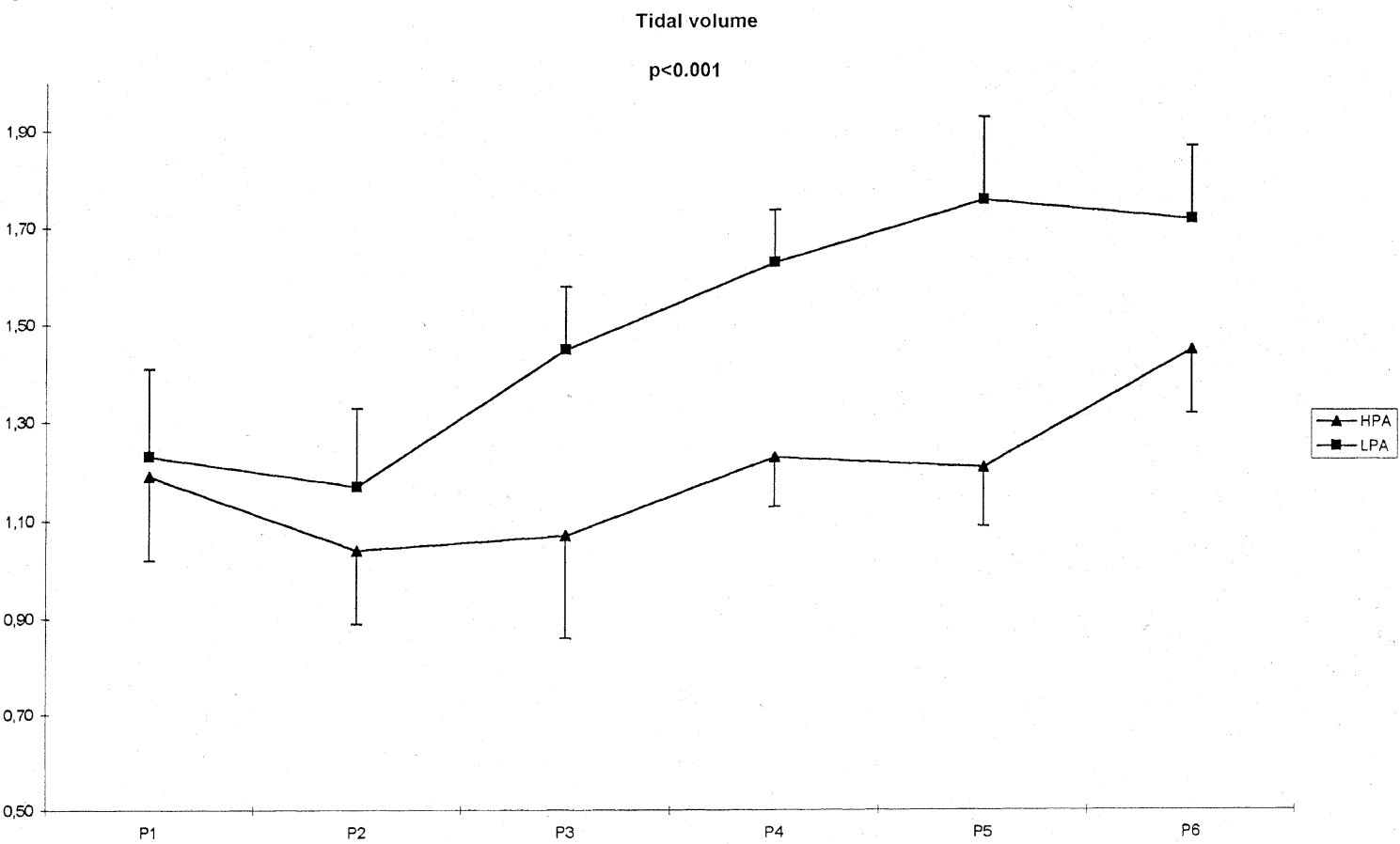

d

Inspiratory time / Total respiratory cycle

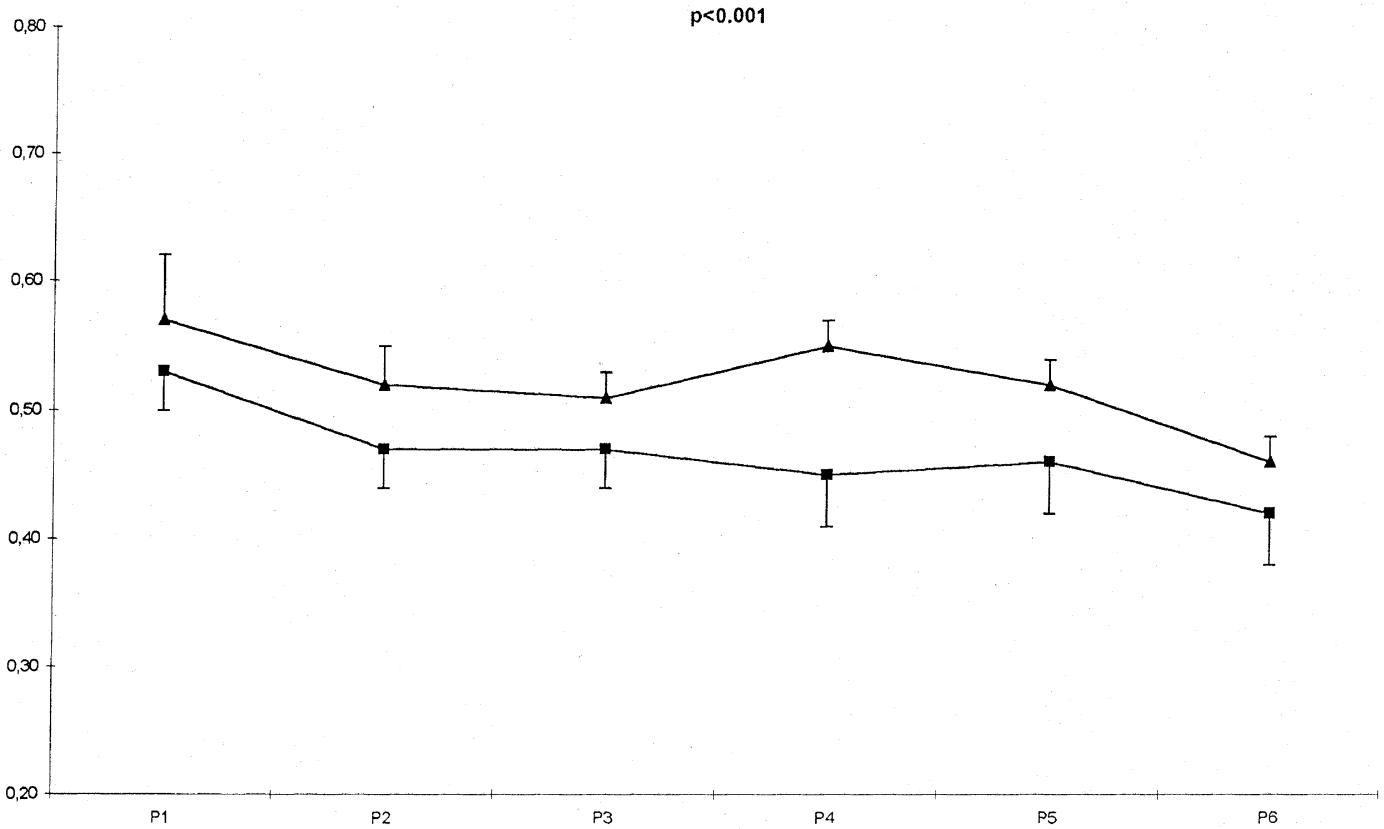

Figure 4 (a-d) Submaximal data of breathing frequency, total respiratory cycle, tidal volume and inspiratory time/total respiratory cycle for the two groups of paraplegics 
daily athletic practice of our subjects may also explain the absence of significant differences in the responses to muscular exercise. Although lesion level must be taken into consideration to understand the adaptations to exercise, several authors have suggested that the cardiorespiratory responses are influenced not only by lesion level, but also by physical activity, which is the best means of increasing exercise tolerance after spinal cord injury. ${ }^{37,38}$

The HPA values of maximal heart rate were higher than those of LPA. Several studies have shown that maximal heart rate is inversely proportional to lesion level during upper arm exercise. ${ }^{4,39}$ These unexpected HR max values differ from the results of Veeger et $a l,{ }^{40}$ who observed values of 170,175 and 182 beats.min ${ }^{-1}$ for classes 2,3 and 4, and from those of Hooker et $a l^{36}$ for classes 2 and 3. In contrast, our results agree with those of Burkett et $a l,{ }^{41}$ who measured mean values of 164 and 160 , respectively, for classes 3 and 4 . The similarity between their results and ours may indicate that in T4-T8 SCI patients, sympathetic involvement does not lead to a maximal heart rate significantly lower than that of paraplegics with a lower lesion level.

In subjects with a high lesion level, it seems that the limiting factors for exercise are of both respiratory and cardiovascular origin. Indeed, the lower maximal values for ventilation, the significant differences in breathing pattern and the vaso-motor disturbances which impede venous return and lead to a higher energy cost, render difficult the adaptations to muscular exercise in high paraplegics. Because the origin of these complications seems to be central rather than peripheral, at the level of the active muscles of the upper extremities, further research is needed to define with more precision the capacities of readaptation of the different cardiovascular and respiratory functions, as well as the training methods best adapted to the optimization of physical capacities.

\section{References}

1 Hughes JT, Phild D. The new neuroanatomy of the spinal cord Paraplegia 1989; 27: 90-98.

2 Mansour M, Sandillon F, Privat A. Transplantation de neurones foëtaux dans la moëlle épinière après section. Neurochirurgie 1986; 32: $507-513$

3 Ragnarsson TS, Durward QJ, Nordgren RE. Spinal cord tethering after traumatic paraplegia with late neurological deterioration. J Neurosurg 1986; 64: 397-401.

4 Attia M, Engel P. Thermoregulatory set-point in paraplegics. In: JRS Hales (ed). Thermal Physiology. New York: Raven Press, 1984, pp. $79-82$

5 Downey J. The spinal patient and thermoregulation. Thermal Physiol 1984; 9: 225-228.

6 Sawka MN, Latzka WA, Pandolf KB. Temperature regulation during upper body exercise: able bodied and spinal cord injuries. Med Sci Sports Exerc 1989; 21: $132-140$.

7 Chu DA et al. Deep venous thrombosis: diagnosis in spinal cord injuries patients. Arch Phy Med Rehabil 1985; 66: 365-368.

8 Frieden RA et al. Venous pletismography values in patient with spinal cord injuries. Arch Phys Med Rehabil 1987; 68: 427-429.
9 Pendergast D. Cardiovascular, respiratory and metabolic responses to upper body exercise. Med Sci Sports Exerc 1989; 21: $121-125$.

10 Chen CF, Lien IN, Wu MC. Respiratory function in patient with spinal cord injuries: effects of posture. Paraplegia 1980; 28: 81 86.

11 De Troyer A, Estenne M. The expiratory muscles in tetraplegia. Paraplegia 1991; 29: 359-363.

12 Fulg-Meyer AR, Grimby G. Respiration in tetraplegia and hemiplegia: a review. Int Rehab Med 1984; 6: 186-190.

13 Cooper RA et al. Prediction of pulmonary function in wheelchair users. Paraplegia 1993; 31: 560 - 570.

14 Hjeltnes N. Cardiorespiratory capacity in tetraplegia and paraplegia shortly after injury. Scand J Rehabil Med 1986; 18: $65-70$.

15 Petrofsky JS, Phillips CA, Hendershot D. Cardio-respiratory stresses which occur during dynamic exercise in paraplegics and quadriplegics. J Neuro Ortho Surg 1985; 6: $252-258$.

16 Brubaker C. Ergonometric considerations. J Rehab Res Dev 1990; (Suppl) 2: 37-48.

17 Brubaker C, McClay I. Determination of the relationship of mechanical advantage with propulsion efficiency. In: Virginia REC (ed). Wheelchair Mobility, 1983, pp. 1-7.

18 Vandanlewijck YC, Spaepan AJ, Lysens RJ. Wheelchair propulsion efficiency: movement pattern adaptations to speed changes. Med Sci Sports Exerc 1995; 26: $1373-1381$.

19 Van der Woude LHV et al. Manual wheelchair propulsion: effects of power output on physiology and technique. Med Sci Sports Exerc 1988; 20: $70-78$.

20 Coutts KD, Rhodes EC, McKenzie DC. Maximal exercise responses of tetraplegics and paraplegics. $J$ Appl Physiol: Respirat Environ Exercise Physiol 1983; 55: 479-482.

21 Ellenberg M. Aerobic capacity in early paraplegia. Paraplegia 1989; 27: $261-268$.

22 Van Loan MD, McClur S, Luftin JM. Comparison of physiological responses to maximal arm exercise among ablebodied, paraplegics and quadriplegics. Paraplegia 1987; 25: $397-$ 405.

23 Miles D, Cox MH, Bomze JP. Cardiovascular responses to upper body exercise in normals and cardiac patients. Med Sci Sports Exerc 1989; 21: $126-131$.

24 Bernard PL, Peruchon E, Micallef JP, Rabischong P. Balance capabilities of wheelchair sportmen. J Rehab Res Dev 1994; 31: $287-296$

25 Figoni SF. Exercise responses and quadriplegia. Med Sci Sports Exerc 1993; 4: 433 - 441

$26 \mathrm{Jehl} \mathrm{JL}$ et al. Aspects bioenergetiques de l'adaptation à l'exercice prolongé chez le paraplégique. Ann Readapt Med Phy 1988; 31: $131-146$.

27 Coutts KD, Rhodes EC, McKenzie DC. Sub-maximal exercise responses of tetraplegics and paraplegics. J Appl Physiol 1985; 59: $237-241$.

28 De Troyer A, Heilporn H. Respiratory mechanics in quadriplegia. The respiratory function of the intercostal muscles. $\mathrm{Am}$ Rev Respir Dis 1980; 122: $591-600$.

29 Jaeger-Denavit O, Leroy M, Liot F. Modification de la spirographie des paraplégiques en différentes positions en l'air et dans l'eau. Bull. Europ Physiopath Resp 1982; 18: 693-704.

30 Fulg-Meyer AR. Effect of respiratory muscle paralysis in tetraplegics and paraplegics patients. Scand J Rehab Med 1971; 3: $141-150$

31 Loveridge BM, Budo HI. Breathing pattern in chronic quadriplegia. Arch Phys Med Rehab 1990; 71: 495-499.

32 Ramanatxo M. Contrôle ventilatoire de l'enfant et de l'adulte jeune face à un acroissement des exigences métaboliques et mécaniques. Thèse de Doctorat d'Etat. Université Montpellier II, 1991.

33 Jammes Y. Chest wall and diaphragmatic afferents: their role during external mechanical loading and respiratory muscle ischemia. In: Grassino et al. (Eds). Respiratory muscle in COPD, 1988 , pp. $49-53$. 
34 Erikson P, Lofstrom L, Ekblom B. Aerobic power during maximal exercise in untrained and well-trained persons with quadriplegia and paraplegia. Scand J Rehab Med 1988; 20: 141 147.

35 Hopman MTE, Oeseburg B, Binkhorst RA. Cardiovascular responses in persons with paraplegia to prolonged arm exercise and thermal stress. Med Sci Sports Exerc 1993; 25: 577-583.

36 Hooker SP et al. Oxygen uptake and heart rate relationship in persons with spinal cord injury. Med Sci Sports Exerc 1993; 25: $1115-1119$.

37 Hooker SP, Wells CL. Effects of low and moderate intensity training in spinal cord injured persons. Med Sci Sports Exerc 1989; 21: $18-22$.
38 Davis GM. Exercise capacity of individuals with paraplegia. Med Sic Sports Exerc 1993; 25: 423 - 432.

39 Gass GC, Camp EM. The maximum physiological responses during incremental wheelchair and arm cranking exercise in male paraplegics. Med Sci Sports Exerc 1984; 16: 355-359.

40 Veeger H, Hadj Yahmed M, Van der Woude LHV, Charpentier P. Peak oxygen uptake and maximal power output of Olympic wheelchair-dependent athletes. Med Sci Sports Exerc 1981; 23: $1201-1209$.

41 Burkett LN, Chisum J, Stone W, Fernhall B. Exercise capacity of untrained spinal cord injured individuals and the relation of peak oxygen uptake to level of injury. Paraplegia 1990; 28: 512-521. 